\title{
Numerical Simulation of the Aircraft Wake Vortex Flowfield
}

\author{
Nash'at N. Ahmad", Fred H. Proctor ${ }^{\dagger}$, R. Brad Perry \\ NASA Langley Research Center, Hampton, Virginia, 23681
}

\begin{abstract}
The near-wake vortex flowfield from a NACA0012 half-wing was simulated using a fully unstructured Navier-Stokes flow solver in three dimensions at a chord Reynolds number of 4.6 million and a Mach number of approximately 0.15 . Several simulations were performed to examine the effects of boundary conditions, mesh resolution, and turbulence scheme on the formation of wingtip vortex and its downstream propagation. The standard SpalartAllmaras turbulence model was compared with the Dacles-Mariani and Spalart-Shur corrections for rotation and curvature effects. The simulation results were evaluated using the data from an experiment performed at NASA Ames' 32in x 48in low speed wind tunnel.
\end{abstract}

\section{Nomenclature}

$\begin{array}{ll}b & =\text { half wingspan } \\ b_{0} & =\text { initial vortex pair separation } \\ c & =\text { chord } \\ C_{\mathrm{p}} & =\text { coefficient of static pressure } \\ C_{\mathrm{L}} & =\text { lift coefficient } \\ \Gamma & =\text { vortex circulation } \\ V_{0} & =\text { initial vortex descent velocity } \\ T_{\text {ref }} & =\text { reference temperature } \\ u_{\infty} & =\text { reference freestream velocity } \\ \operatorname{Re} & =\text { Reynolds number } \\ \mathrm{Ma} & =\text { Mach number } \\ r_{\mathrm{c}} & =\text { vortex core radius } \\ x & =\text { streamwise direction } \\ y & =\text { vertical direction } \\ z & =\text { spanwise direction } \\ u & =\text { axial velocity }\end{array}$

\section{Introduction}

$\mathrm{W}$ AKE vortex studies conducted in the past can be divided roughly into two focus areas: near-wake and farwake. The near-wake region extends about 10-50 wingspans behind the generating aircraft and is dominated by the roll-up of multiple vortices off the wing surface, flaps, and tail. At greater distances, i.e., in the far-wake region, these multiple vortices coalesce into a counter-rotating vortex pair and the ambient meteorological conditions dominate vortex transport and decay. The development of operational tools and concepts of operations has been driven by the far-wake research. These studies have relied on either large eddy simulations (e.g., Han et al. 2000; Proctor 2009) or field experiments (Hinton 1995; Perry et al. 1997) and have resulted in a wealth of knowledge leading to a better understanding of wake decay and transport under varying conditions of atmospheric turbulence and stratification. The experimental and simulation data have been utilized for the development of fasttime wake prediction models (Sarpkaya et al. 2001; Holzäpfel 2006; Proctor and Hamilton 2009). The fast-time wake models can be used for the systems level design of advanced air traffic management (ATM) concepts that safely increase the capacity of the National Airspace System (NAS). It is also envisioned that at some later stage of maturity, these models could be used operationally, not only within the terminal airspace but also as onboard tools to support concepts such as dynamic separation of aircraft.

\footnotetext{
* Research Aerospace Engineer, NASA, Hampton, Virginia. Senior Member, AIAA.

${ }^{\dagger}$ Senior Research Scientist, NASA, Hampton, Virginia. Senior Member, AIAA.

*Wake Vortex Technical Lead, NASA, Hampton, Virginia. Senior Member, AIAA.
} 
Near-wake behavior is important for at least two reasons: 1) understanding and deriving initial conditions for farwake models, and 2) assessing the hazard of a near-wake encounter such as due to a blunder from a parallel approach. The near-wake studies have focused on understanding vortex roll-up and have been limited to a small range of flow conditions and Reynolds numbers. Research on how to use the information from near-wake analyses in operational tools and concepts has also been limited. One reason for this restriction can be attributed to the high computational cost of running near-wake simulations. In recent years, great strides have been made in highperformance computing and computational fluid dynamics (CFD) techniques. The availability of powerful computing resources allows researchers to attempt the detailed analysis of wake turbulence in the near field of an aircraft. The CFD analysis can not only lead to a better understanding of the vortex roll-up process, but can also provide better initial conditions for the large eddy simulation (LES) codes and the fast-time wake models - thus bridging the gap between the near-wake research and the far-wake research efforts. For example, fast-time wake models require as inputs the initial vortex pair separation $\left(b_{0}\right)$ and the initial vortex pair descent velocity $\left(V_{0}\right)$, which are usually based on the assumption of elliptic wing loading (Betz 1933). The large eddy simulation codes are also initialized with simple idealized models, based on a fully rolled-up vortex pair. The radial distributions of tangential velocity $\left(v_{\theta}\right)$ and circulation $(\Gamma)$ in these idealized models are represented by various relationships. The idealized wake vortex models use vortex core radius $\left(r_{\mathrm{c}}\right)$ as one of the inputs and various estimates ranging from 1\% to $7 \%$ of the wingspan have been suggested in literature (Delisi et al. 2003). Even less understood are the appropriate axial velocity profiles for LES initialization. In the wind tunnel studies (Chow et al. 1997) as well as field experiments (Figure 1), significant axial velocity components have been measured and observed. The CFD simulations can provide information on the intensity and distribution of the axial velocity behind the aircraft. The lack of flow field and wake behavior data at early stages can introduce uncertainties in the design of ATM concepts such as closely spaced parallel runway (CSPR) operations. In blunder scenarios, e.g., during CSPR operations, an understanding of wakes which are not fully rolled up would be essential for determining the safety envelope of the procedure.

Several experimental studies have been conducted in the past to characterize wake rollup from the wingtip (Chigier and Corsiglia 1972; Takahashi 1987; Chow et al. 1997; Gingras et al. 2001; Delisi 2012). These studies have provided not only insight into the wake phenomenon but also useful data for the validation of numerical codes. The main limitation of these studies is that they have been conducted at a small range of relatively low Reynolds numbers and using few test configurations. During actual flight conditions, however, the Reynolds numbers are much higher than can be obtained in experiments. Previous near-wake numerical studies (Dacles-Mariani et al. 1995; Churchfield et al. 2011) have focused on the effects of mesh resolution, boundary conditions and turbulence schemes on the accuracy of the computed solution of the roll-up from a wingtip. In some recent studies, attempts have been made to simulate the wake rollup using the complete aircraft. For example, Takashi et al. (2012) used fuselage-wing geometry to generate initial conditions for LES and Jurkovich (2011) simulated the wake behind a KC-135 tanker. In the present study, the National Aeronautics and Space Administration's (NASA) Fully Unstructured Navier-Stokes 3D (FUN3D) code (Anderson and Bonhaus 1994; Anderson et al. 1995; Nielsen 1998) is used to simulate in detail the wake in the near field of a NACA0012 half-wing. In the following sections, NASA's FUN3D code and the wind tunnel test are briefly described, and the results of numerical simulations are presented.

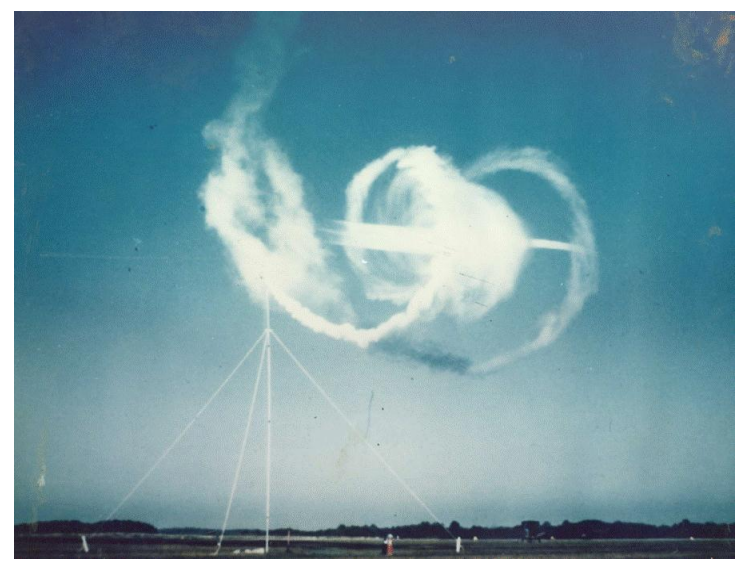

Figure 1. Wake vortex experiment conducted at NASA Langley Research Center in the early 1970s. Axial flows can be seen at the center of the vortex. 


\section{The Fully Unstructured Navier-Stokes 3D (FUN3D) Code}

The Fully Unstructured Navier-Stokes 3D is a versatile code that has been used to solve complex flow problems ranging from hypersonics to aeroacoustics (http://fun3d.larc.nasa.gov/index.html). FUN3D is based on a nodecentered, finite-volume scheme designed to compute both compressible and incompressible flows on grids with different types of elements (tetrahedral, pyramid, prism and hexahedral elements, mixed-elements). The solver uses an artificial compressibility method for incompressible flows (Anderson et al. 1995). Several schemes are available for computing the convective fluxes. Computations of viscous fluxes on tetrahedral meshes are based on the GreenGauss theorem and calculations on non-tetrahedral meshes are based on an edge-based approach to avoid odd-even decoupling. A number of turbulence models have been implemented in the code that range from single equation models to hybrid Reynolds-Averaged Navier-Stokes (RANS)/LES capability. Time integration is based on a backwards-Euler scheme with local time-stepping to accelerate convergence.

\section{Wind Tunnel Test}

Chow, Zilliac and Bradshaw (1997) conducted detailed wind tunnel studies to characterize the turbulent flow field in the near wake of a half-wing. The experiments were conducted in the $32 \mathrm{in} \times \mathrm{x} 48 \mathrm{in}$ low speed wind tunnel at the Fluid Mechanics Laboratory of NASA Ames Research Center. A rectangular half-wing model with NACA 0012 section was used in the study (Figure 2). The half-wing had a span of $3 f t$ and a $4 f t$ chord (aspect ratio of 0.75 ). The wingtip was rounded (half-body of revolution) - the constant chord section of the wing section was 33.12in. The maximum extension of the wingtip near the quarter chord was $2.88 \mathrm{in}$. The wing trailing edge was squared-off (0.121 in thickness). The angle of attack of the half-wing was set to $10^{\circ}$ relative to freestream. The quarter chord point of the wing model was $19 \mathrm{in}$ downstream of the test section inlet. The freestream velocity, $u_{\infty}$ was $170 \mathrm{ft} / \mathrm{s}$ $(51.82 \mathrm{~m} / \mathrm{s})$ and the Reynolds number based on the chord length was 4.6 million. The flow was made fully turbulent by placing a 1/8in-wide line of 0.017in-diameter roughness elements on the upper and lower wing surface at a distance of $2 \mathrm{in}$ from the leading edge. Detailed measurements were taken using static pressure taps on the wing surface. Turbulence, velocity, and pressure measurements were taken at various planes along the wind tunnel ranging from $x / c=-0.591$ to $x / c=0.678$, where $c$ is the wing chord length. Triple hot-wire anemometry was used for turbulence measurements in the wake region and a higher density of probes was placed in the vortex core region.

\section{Results}

\section{A. Simulation Setup}

Dacles-Mariani et al. $(1993 ; 1995 ; 1996)$ conducted a series of simulations for this case to support the wind tunnel experiment. Their computational domain consisted of the entire test section of the wind tunnel. The length of the domain was $1.813 c$ (87in), the width was $1.0 c$ (48in), and the height was $0.667 c$ (32in). The simulation setup suggested by Dacles-Mariani et al. (1995) placed the inflow and outflow boundaries very close to the wing. A similar setup was used by Nichols (2008), Nichols et al. (2008) and Uzun et al. (2005). To avoid problems at the inflow and outflow boundaries, some recent studies (Kim and Rhee 2005; Churchfield and Blaisdell 2009; Churchfield and Blaisdell 2011; Goparaju and Zhuang 2012) have recommended larger domains. In this study, the domain was similar to the one suggested by Churchfield and Blaisdell (2011) in which the inflow boundary was placed at $2.5 c$ from the trailing edge and the outflow boundary at $3.0 c$ from the trailing edge (Figure 2). The meshes were generated using the VGRID software (Pirzadeh 1996). The viscous spacing on the wing was set to $1 \times 10^{-6} c$. The tunnel walls had the same viscous spacing. A maximum stretch ratio of 1.1 was specified in the viscous region for the generation of volume grid. In previous studies, the viscous spacing on the wind tunnel walls was much coarser compared to the spacing on the wing surface.

Earlier studies have emphasized the need for higher-order schemes for resolving the vortex core. DaclesMariani et al. (1995) recommended using at least a $5^{\text {th }}$-order spatially accurate scheme. Nichols et al. (2008) compared two $5^{\text {th }}$-order weighted essentially nonoscillatory (WENO) schemes with a $3^{\text {rd }}$-order scheme and found that the $3^{\text {rd }}$-order scheme was too diffusive and not able to accurately resolve the wingtip vortex and its propagation. The mesh spacing in the vortex core region in these studies was set to $0.01 c$ in the streamwise direction and $0.005 c$ (0.24in) in the spanwise direction. This placed 11 to 20 points across the vortex core depending on how the mesh refinement was prescribed in the vortex core region. In the current study, a high mesh resolution was specified in the vortex core region by placing cylindrical refinement sources along the vortex core line. Two meshes (Figure 3 ) were generated with resolutions of $0.2 \mathrm{in}$ and $0.1 \mathrm{in}$ around the vortex core. 
The inflow Mach number based on the freestream conditions was 0.1509 and the reference temperature, $T_{\text {ref }}$ was set to $20^{\circ} \mathrm{C}$. The Reynolds number was 4.6 million. Total temperature and total pressure based on the wind tunnel data were specified at the inflow boundary and static pressure was specified at the outflow boundary. Although the Mach number is low, several studies in the past have used compressible solvers without pre-conditioning (Nichols et al. 2008; Churchfield and Blaisdell 2009) and obtained results comparable to incompressible solutions (DaclesMariani et al. 1995). FUN3D can be used for both compressible and incompressible flows and both options were tested. The results of the compressible solver are presented in this paper. The solution convergence was based on reduction in the residuals by several orders of magnitude and forces on the wing to become steady. The axial velocity was also monitored at a reference point inside the tunnel (at this point, $u / u_{\infty}=1$ in the wind tunnel data). The reference point is at $x=-1.135 c, y=0.342 c$ and $z=1.05 b$. Convergence was reached within 3500-5000 iterations for all cases.

Dacles-Mariani et al. $(1995 ; 1996)$ found that the standard turbulence models were not able to accurately predict the vortex pressure and velocity as well as the vortex core radius. The schemes predicted diffused vortices with increasing core radii. They suggested modifications be made to the production term of the turbulence model to decrease excessive diffusion in the vortex core. The Dacles-Mariani modification has since been used in several studies with favorable results. Kim and Rhee (2005) evaluated several turbulence schemes and found that the Reynolds Stress Transport Model (RSTM) described in Kim (2001) and the Spalart-Allmaras (SA) model with Dacles-Mariani correction gave the best results. Uzun et al. (2005) used LES for this case but at $\operatorname{Re}=0.5$ million, and therefore their computational results did not agree well with the experimental data. In this study, the SA model is examined with both Dacles-Mariani et al. $(1995 ; 1996)$ and Shur et al. (2000) corrections for rotation and curvature effects.

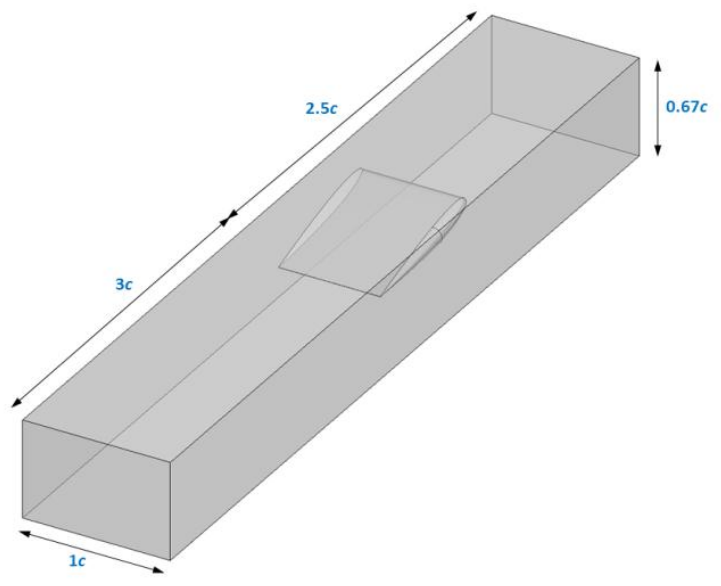

Figure 2. The computational domain for the wing-wind-tunnel configuration is shown. The inflow and outflow boundaries were extended in the simulations.
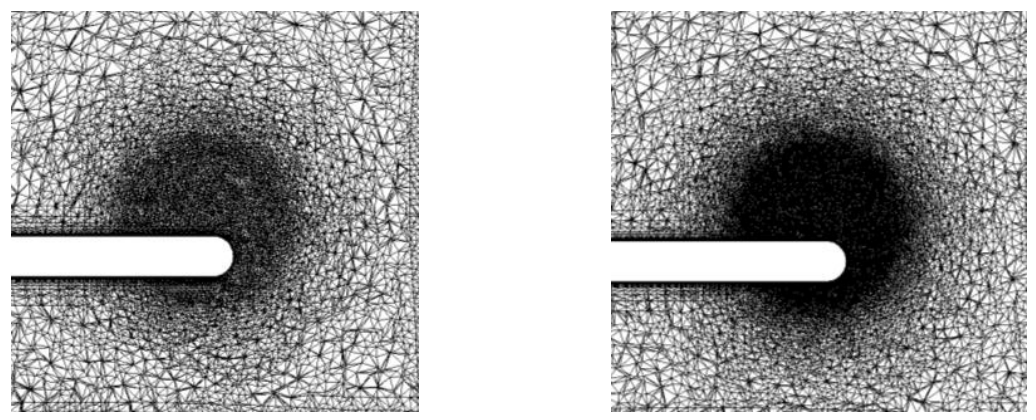

Figure 3. Mesh with coarse resolution (0.2in) around the vortex core near the wingtip is shown in the left panel and the mesh with fine resolution (0.1in) around the vortex core region is shown in the right panel.

\section{B. Comparison with Wind Tunnel Data}


The wind tunnel coordinate systems are used in the plots presented in this section. In the wind-tunnel experiment, the $z$-axis is spanwise, the $y$-axis is vertical, and the $x$-axis is in the streamwise direction.

\section{Surface Static Pressure Coefficient}

Comparison of the computed $C_{\mathrm{p}}$ with the wind tunnel data at different locations over the half-wing is shown in Figure 4, and the contours of the computed $C_{\mathrm{p}}$ over both the upper and lower wing surfaces are shown in Figure 5. The solutions are for the fine mesh using the Dacles-Mariani correction in the SA model. The simulated results are in good agreement with the experimental data. However, near the wingtip, there are discrepancies due to the inadequacy of the model to fully resolve the vortex formation. Figure 6 shows the comparison of computed $C_{\mathrm{p}}$ using the standard SA model with both the Dacles-Mariani and the Spalart-Shur corrections. Near the wing root, all three models gave identical results but near the wingtip the $C_{\mathrm{p}}$ prediction was slightly improved by using the Spalart-Shur correction.
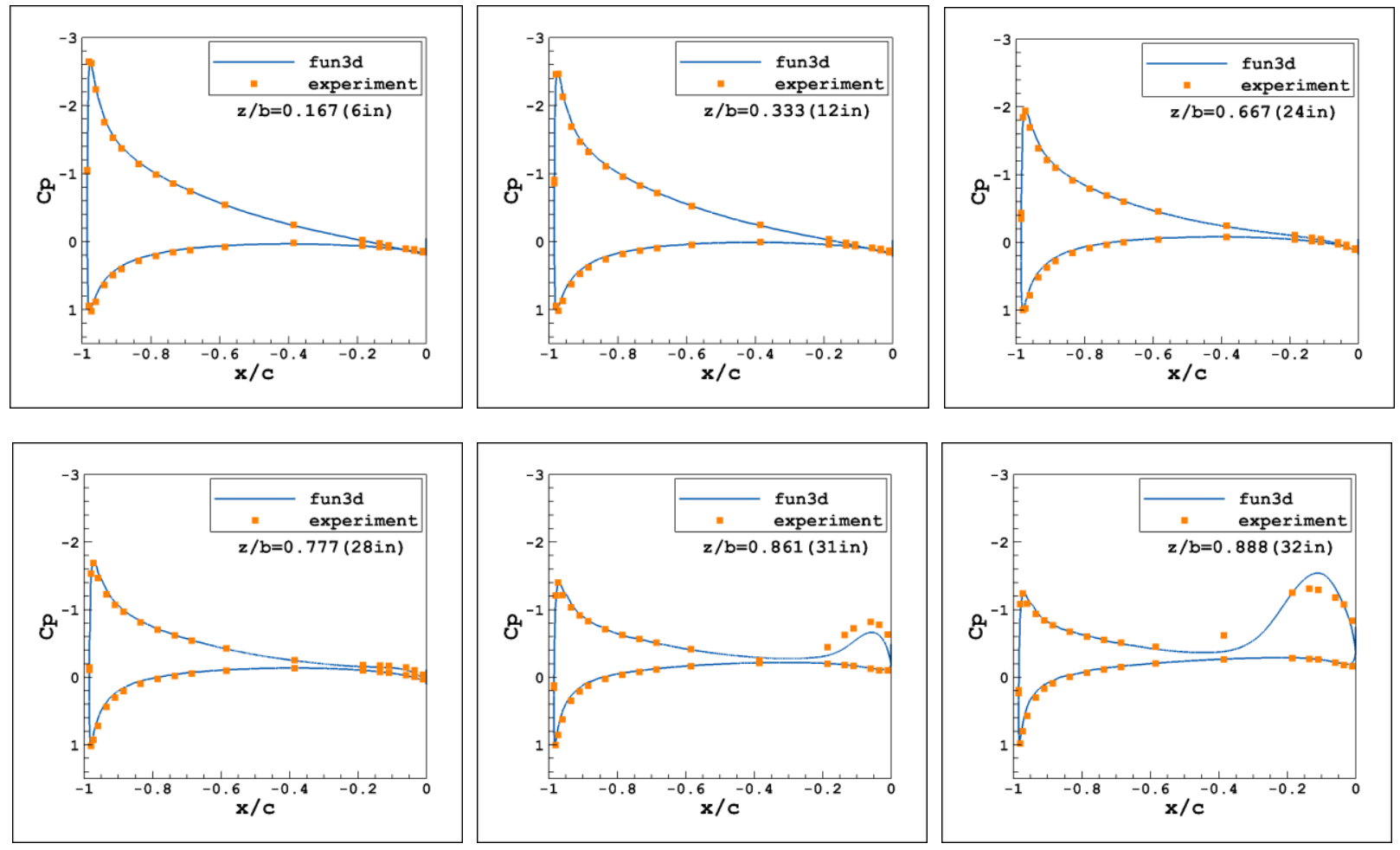

Figure 4. Comparison of the computed static pressure coefficient $\left(C_{\mathrm{p}}\right)$ with wind tunnel data at different locations over the half-wing. Solution on the fine mesh using SA model with Dacles-Mariani correction.
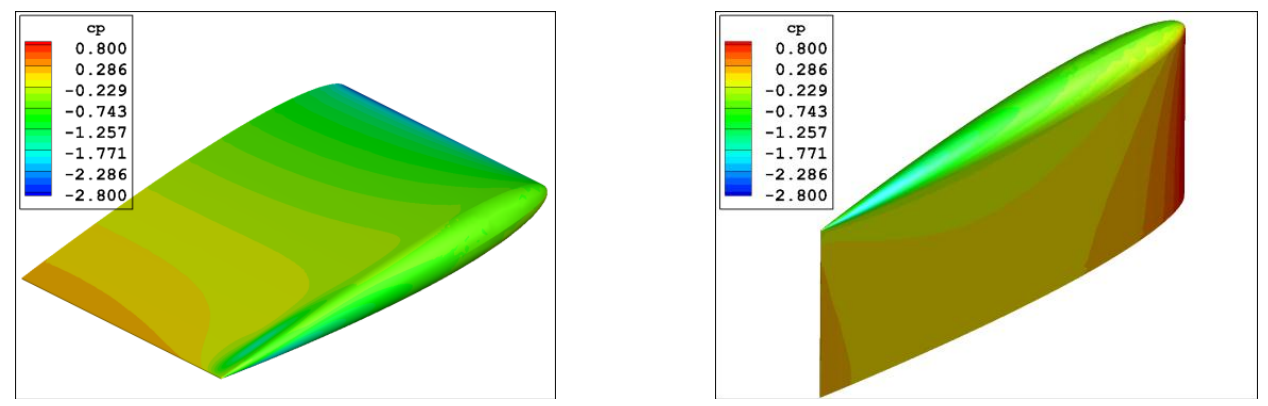

Figure 5. Computed coefficient of static pressure $\left(C_{\mathrm{p}}\right)$. The left panel shows the contours on the suction side (upper surface) of the wing and the right panel shows the contours on the pressure side of the wing. Solution on the fine mesh using SA model with Dacles-Mariani correction. 
The computed lift coefficient $\left(C_{\mathrm{L}}\right)$ on the fine mesh using Dacles-Mariani correction was 0.548 , compared to 0.549 reported by Dacles-Mariani (1996) and 0.84 reported in Goparaju and Zhuang (2012). The experimental $C_{\mathrm{L}}$ was 0.51 , but Chow et al. (1997) have expressed reservations on the accuracy of the measured value given the wind tunnel test setup. In the wind tunnel experiment, the flow was tripped and made fully turbulent by placing roughness elements on the upper and lower wing surfaces near the leading edge. Dacles-Mariani (1996) included transition in their computations but reported no difference in results and therefore computed only the fully turbulent flow. Rumsey and Lee-Rausch (2012) accounted for transition which resulted in an improved $C_{\mathrm{L}}$ prediction. In this study, fully turbulent flow was assumed and the effect of including transition is something that can be looked into in a future study.
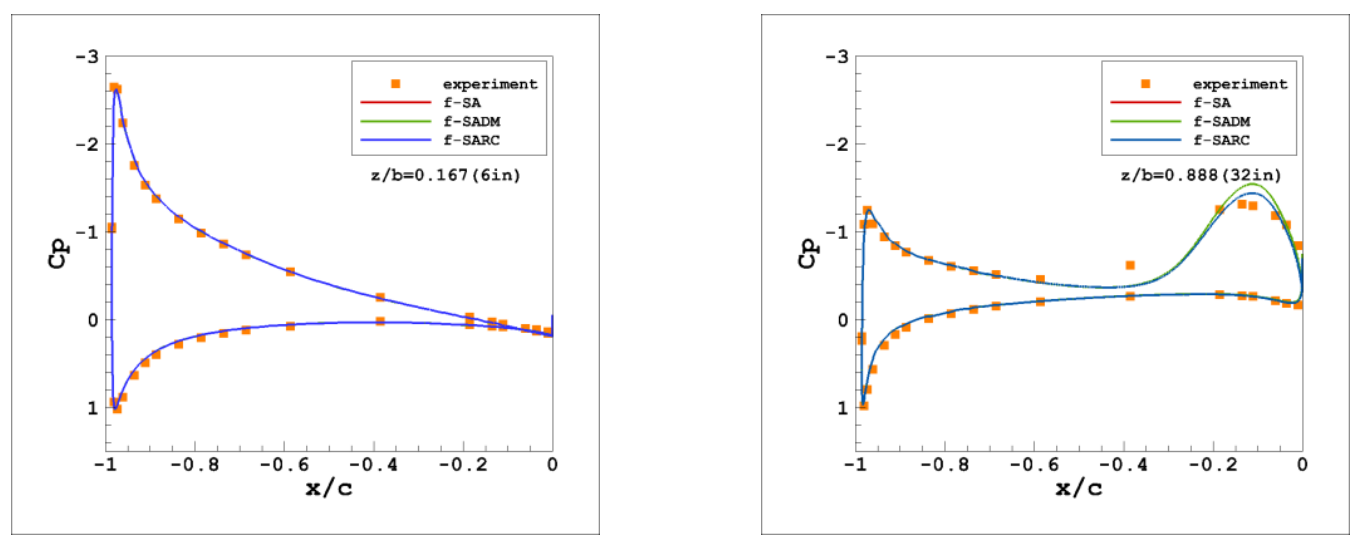

Figure 6. Comparison of the computed static pressure coefficient $\left(C_{\mathrm{p}}\right)$ with wind tunnel data near the wing root (left panel) and near the wingtip (right panel). In the legend, ' $f$ ' stands for solution on the fine mesh. SA is the standard Spalart-Allmaras model, SADM is the SA model with Dacles-Mariani correction and SARC is the SA model with Spalart-Shur correction.

\section{Axial Velocity}

Figure 7 shows cutplanes of computed axial velocity normalized by $u_{\infty}$ at different locations. The computed axial velocity is compared with measurements along the vortex core line in Figure 9. The sensitivity to mesh resolution and the turbulence scheme is clearly observed in the computed solutions. The coarse mesh was not able to resolve the initial formation of the vortex at the wingtip and, in the case of standard SA model, the vortex dissipates rapidly - even on the fine mesh. The predicted values of the peak axial velocity at the trailing edge for the fine mesh were $1.61 u_{\infty}, 1.76 u_{\infty}$, and $1.77 u_{\infty}$ for the SA, SA-Dacles-Mariani, and the SA-Spalart-Shur models, respectively. The maximum measured axial velocity was $1.77 u_{\infty}$ near the trailing edge of the wing.

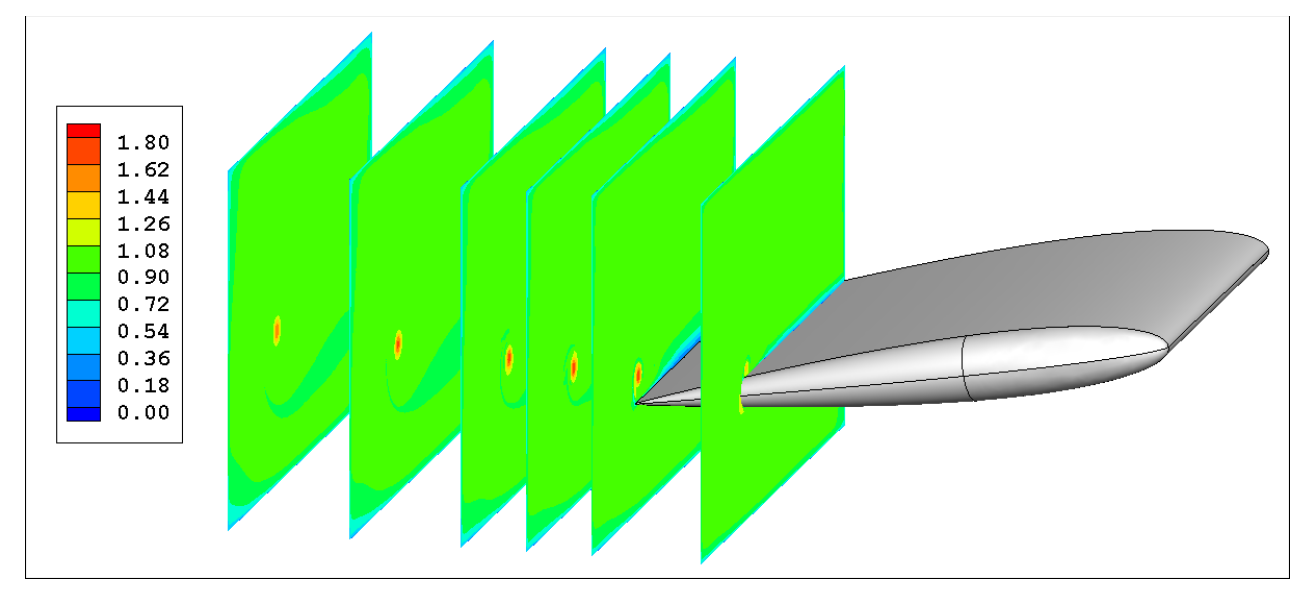

Figure 7. Cutplanes of the computed axial velocity normalized by $\boldsymbol{u}_{\infty}$ at different locations. Solution on the fine mesh (SA model with Spalart-Shur correction). 


\section{Vortex Static Pressure Coefficient}

Figure 8 shows cutplanes of the computed coefficient of static pressure at different locations. The computed $C_{\mathrm{p}}$ is compared with measurements along the vortex core line in Figure 9. Use of a coarse mesh and the standard SA model (even on the fine mesh) resulted in large errors in the predicted values of $C_{\mathrm{p}}$. The SA model with both Dacles-Mariani and Spalart-Shur corrections on the fine mesh are in good agreement with measurements until the trailing edge but, after the vortex lifts off from the wing, the Spalart-Shur correction gives better values for $C_{\mathrm{p}}$. The predicted values of the minimum $C_{\mathrm{p}}$ at the trailing edge for the fine mesh were -2.95, -3.3, and -3.4 for the SA, SADacles-Mariani, and the SA-Spalart-Shur models respectively.

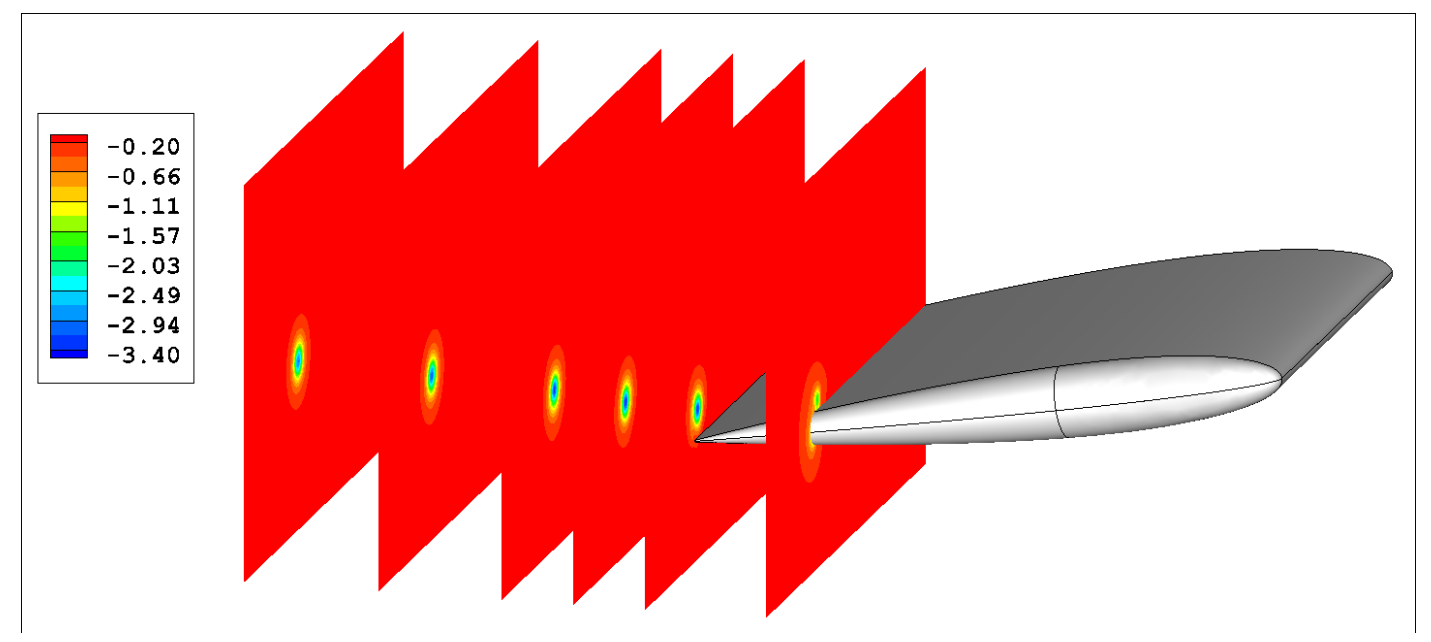

Figure 8. Cutplanes of static pressure coefficient $\left(C_{\mathrm{p}}\right)$ at different locations. Solution on the fine mesh (SA model with Spalart-Shur correction).
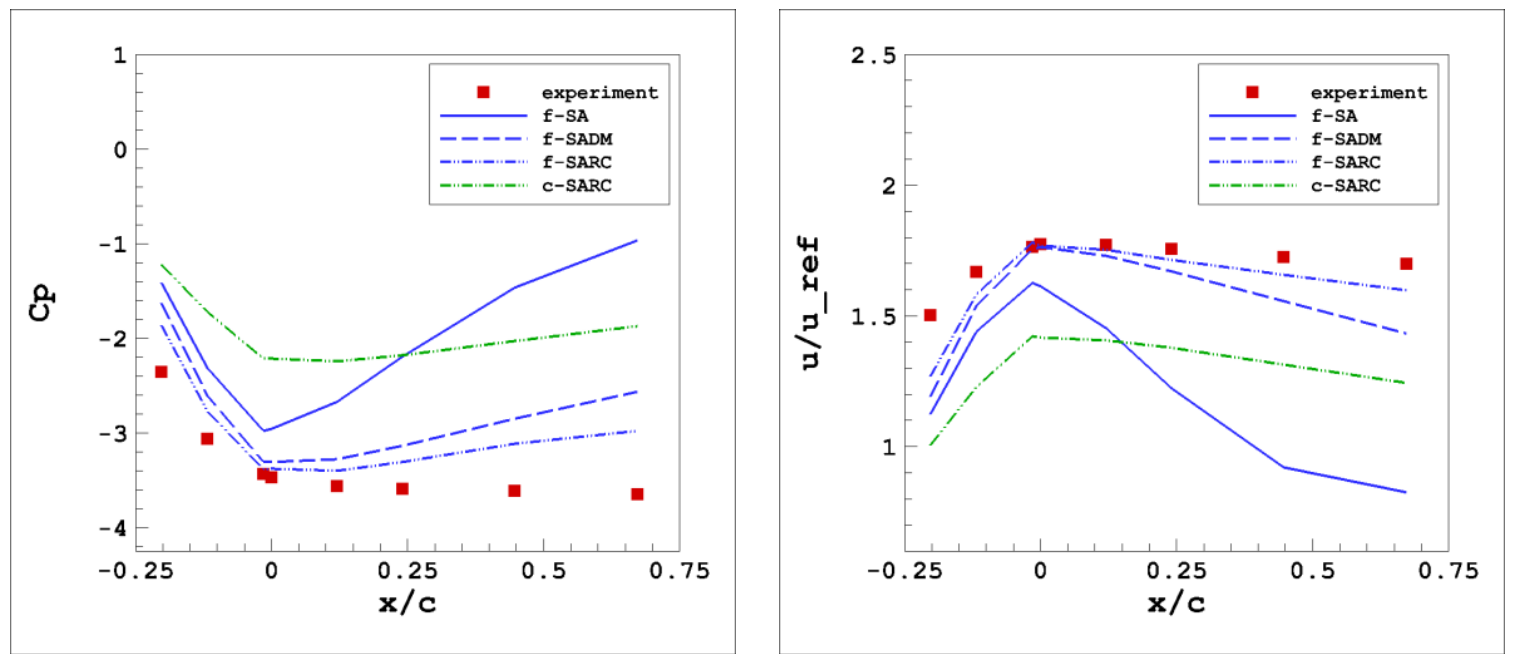

Figure 9. Comparison of the computed static pressure coefficient $\left(C_{\mathrm{p}}\right)$ and the normalized axial velocity $\left(u / u_{\infty}\right)$ with wind tunnel data along the vortex core centerline. In the legend, ' $f$ ' stands for the fine mesh and 'c' stands for the coarse mesh. SA is the standard Spalart-Allmaras model, SADM is the SA model with Dacles-Mariani correction, and SARC is the SA model with Spalart-Shur correction. 


\section{Vortex Core Location}

The predicted vortex core locations are compared with measurements in Figure 10. The predicted positions by different models were similar and in reasonable agreement with the experimental data. The SA model with SpalartShur correction on the fine mesh gave a slightly better prediction of the vortex core location.
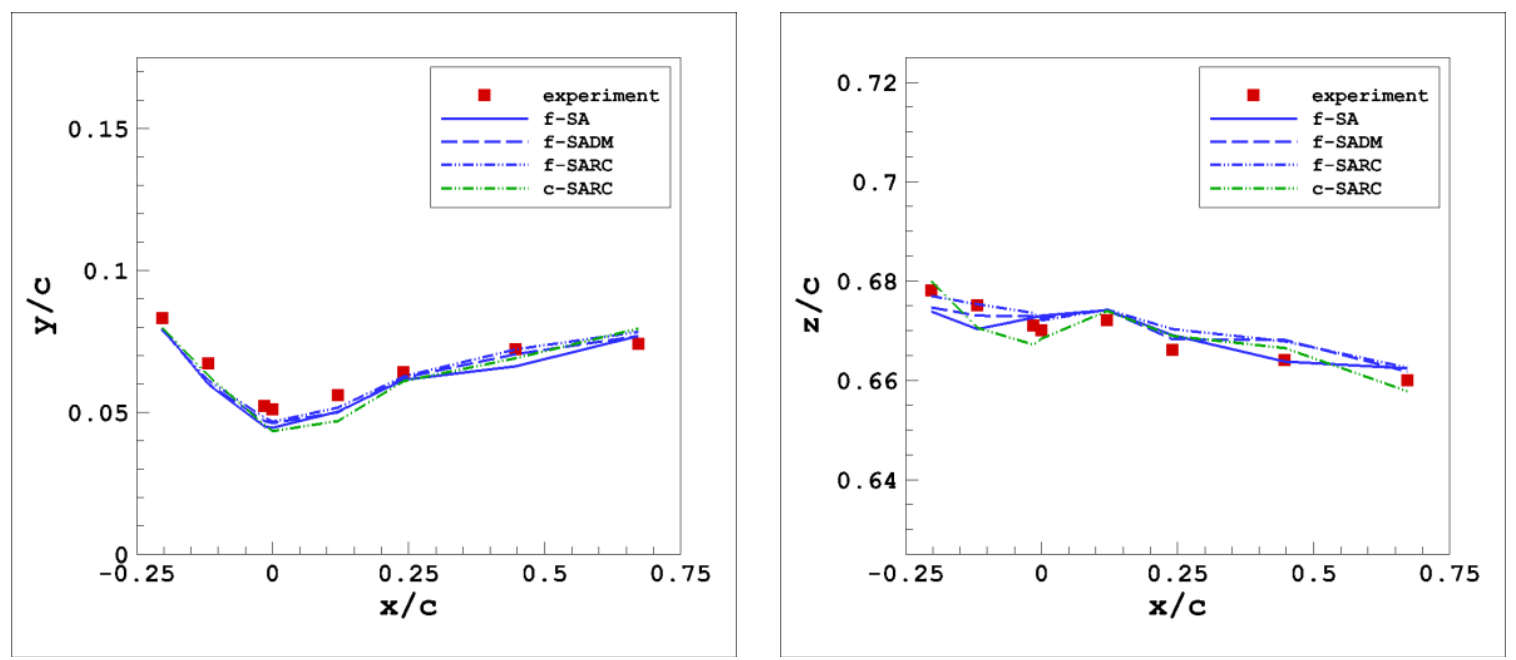

Figure 10. Comparison of the computed vortex core locations with the wind tunnel data. In the legend, 'f' stands for the fine mesh and ' $c$ ' stands for the coarse mesh. SA is the standard Spalart-Allmaras model, SADM is the SA model with Dacles-Mariani correction, and SARC is the SA model with Spalart-Shur correction.

\section{Summary}

Numerical simulations of the near-wake flowfield were performed using a fully-unstructured Navier-Stokes flow solver, and the results were compared against wind tunnel measurements. The solution was sensitive to boundary conditions and the inflow and outflow boundaries had to be placed farther out to avoid numerical problems. A mesh refinement study showed that a $0.0021 c$ grid size resolution was needed in the vortex core region to adequately resolve the formation of the vortex at the wingtip and its downstream propagation. This resolution is more than a factor of 2 higher than previously suggested values (Dacles-Mariani et al. 1996). Dacles-Mariani et al. (1996) used a fifth-order scheme whereas the current study was performed using a second-order accurate flow solver. Simulations were run with the standard SA model and SA with the Dacles-Mariani and Spalart-Shur corrections. All turbulence models were able to predict the vortex location reasonably well and there was less dependence on mesh resolution. However, there were substantial differences in the prediction of axial velocity and $C_{\mathrm{p}}$ in the vortex core. The SA model with Spalart-Shur correction gave the best predictions in the wake region and also improved the $C_{\mathrm{p}}$ near the wingtip. The modified term in the Dacles-Mariani correction had almost no effect in the boundary layer but improved the solution in the wake region. Future extension of this work will focus on the simulation of wingtip vortex using either the Common Research Model (CRM) geometry or the Drag Prediction Workshop (DPW) geometry in order to provide initial conditions for large eddy simulations.

\section{Acknowledgments}

This work is sponsored under NASA's Concepts \& Technology Development Project of the Airspace Systems Program. Many thanks to Norma Farr and Mike Wiese for creating the wing/wind-tunnel geometry and generating the meshes. The FUN3D simulations were performed on NASA's Pleiades and K clusters. The authors would like to acknowledge Fanny Limon Duparcmeur for assisting in post-processing the simulation data.

\section{References}

Anderson, W.K., R.D. Rausch, and D.L. Bonhaus, "Implicit/Multigrid Algorithms for Incompressible Turbulent Flows on Unstructured Grids", AIAA Paper 1995-1740. 
Anderson, W.K., and D.L. Bonhaus, "An Implicit Upwind Algorithm for Computing Turbulent Flows on Unstructured Grids", Computers and Fluids, Vol. 23, 1994, pp. 1-22.

Betz, A., "Verhalten von Wirbelsystemen (Behavior of Vortex Systems)", National Advisory Council on Aeronautics, NACA-TM-713, 1933, 23 pp.

Chigier, N. and V. Corsiglia, "Wind-Tunnel Studies of Wing Wake Turbulence”, Journal of Aircraft, Vol. 9, 1972, pp. 820825.

Chow, J., G. Zilliac, and P. Bradshaw, "Turbulence Measurements in the Near Field of a Wingtip Vortex", NASA-TM 110418, 1997.

Churchfield, M.J., and G.A. Blaisdell, "Near Field Wingtip Vortex Computation Using the WIND Code”, AIAA Paper 20060633.

Churchfield, M.J., and G.A. Blaisdell, "Numerical Simulation of a Wingtip Vortex in the Near Field”, Journal of Aircraft, Vol. 46, 2009, pp. 230-243.

Churchfield, M.J., and G.A. Blaisdell, “A Reynolds Stress Relaxation Turbulence Model Applied to a Wingtip Vortex Flow”, AIAA Paper 2011-0663.

Corjon, A., D. Darracq, S. Champagneux, and F. Laporte, "Wake Roll-up Simulation up to Far-Field”, AIAA Paper 19993201.

Dacles-Mariani, J., S. Rogers, D. Kwak, G. Zilliac, J. Chow, “A Computational Study of Wingtip Vortex Flowfield”, AIAA Paper 1993-3010.

Dacles-Mariani, J., D. Kwak, G. Zilliac, “Accuracy assessment of a wingtip vortex flowfield in the near-field region”, AIAA Paper 1996-0208.

Dacles-Mariani, J., G. Zilliac, J. Chow, and P. Bradshaw, "Numerical/Experimental Study of a Wingtip Vortex in the Near Field”, AIAA Journal, Vol. 33, 1995, pp. 1561-1568.

Delisi, D.P., G.C. Greene, R.E. Robins, D.C. Vicroy, F.Y. Wang, “Aircraft Wake Vortex Core Size Measurements”, AIAA Paper 2003-3811.

Delisi, D.P., “Turbulence Measurements in the Wakes of Aircraft and Model laboratory Wings”, AIAA Paper 2012-0427.

Gingras, D. R., J. L. Player, and W. B. Blake, "Static and Dynamic Wind Tunnel Testing of Air Vehicles in Close Proximity", AIAA Paper 2001-4137.

Goparaju, K., M. Zhuang, "Numerical Simulation of Wingtip Vortices”, AIAA Paper 2012-3328.

Han, J., Y. Lin, P. Arya, and F. Proctor, "Numerical Study of Wake Vortex Decay and Descent in Homogeneous Atmospheric Turbulence”, AIAA Journal, Vol. 38, 2000, pp. 643-656.

Hinton, D.A., “Aircraft Vortex Spacing System (AVOSS) Conceptual Design”, NASA Technical Memorandum NASA-TM110184, 1995.

Holzäpfel, F., "Probabilistic Two-Phase Aircraft Wake-Vortex Model: Further Development and Assessment," Journal of Aircraft, Vol. 43, No. 3, March-April 2006, pp. 700-708.

Jurkovich, M.S., "CFD Prediction of the Flowfield behind the KC-135R Tanker”, AIAA Paper 2011-3510.

Kim, S., "Unstructured Mesh Based Reynolds Stress Transport Modeling of Complex Turbulent Shear Flows", AIAA Paper 2001-0728.

Kim, S., S.H. Rhee, "Prediction of Tip-Vortex Flow Past a Finite Wing”, AIAA Paper 2005-0058.

Lang, S., Tittsworth, J., Domino, D., Lunsford, C., Clark, D., Robasky, F., and Lohr, G., "Wake Turbulence Mitigation for Departures from Closely Spaced Parallel Runways: A Research Update," $1^{\text {st }}$ CEAS European Air and Space Conference, 10-13 September 2007, CEAS-2007-176, pp. 3371-3381. 
National Research Council, Wake Turbulence: An Obstacle to Increased Air Traffic Capacity, Report by the National Research Council of the National Academies, 2008.

Nichols, R.H., “Algorithm and Turbulence Model Requirements for Simulating Vortical Flows”, AIAA Paper 2008-0337.

Nichols, R.H., R.W. Tramel, P.G. Buning, "Evaluation of Two High-Order Weighted Essentially Nonoscillatory Schemes", AIAA Journal, Vol. 46, No. 12, 2008, pp. 3090-3102.

Nielsen, E.J., Aerodynamic Design Sensitivities on an Unstructured Mesh Using the Navier-Stokes Equations and a Discrete Adjoint Formulation, Ph.D. thesis, Virginia Polytechnic Institute and State University, 1998.

Perry, R. B., D.A. Hinton, and R.A. Stuever, “NASA Wake Vortex Research for Aircraft Spacing,” AIAA-1997-0057.

Proctor, F. and D. Hamilton, "Evaluation of Fast-Time Wake Vortex Prediction Models", AIAA Paper 2009-0344.

Pirzadeh, S., "Three-dimensional Unstructured Viscous Grids by the Advancing Layer Method", AIAA Journal, Vol. 33, 1996, pp. 43-49.

Proctor, F., "Interaction of Aircraft Wakes from Laterally Spaced Aircraft", AIAA Paper 2009-0343.

Roe, P. L., “Approximate Riemann Solvers, Parameter Vectors, and Difference Schemes”, Journal of Computational Physics, Vol. 43, 1981, pp. 357-372.

Rumsey, C.L. and E.M. Lee-Rausch, "NASA Trapezoidal Wing Computations Including Transition and Advanced Turbulence Modeling”, AIAA Paper 2012-2843.

Sarpkaya, T., Robins, R.E., and Delisi, D.P., "Wake-Vortex Eddy-Dissipation Model Predictions Compared with Observations," Journal of Aircraft, Vol. 38, 2001, pp. 687- 692.

Spalart, P.R., and S.R. Allmaras, “A One-Equation Transport Model for High Reynolds Number Wall-Bounded Flows”, AIAA Paper 1992-0439.

Shur, T., M.L., M.K. Strelets, A.K. Travin, P.R. Spalart, “Turbulence Modeling in Rotating and Curved Channels: Assessing the Spalart-Shur Correction," AIAA Journal, Vol. 38, 2000, pp. 784- 792.

Takahashi, R., and K. McAlister, "Preliminary Study of a Wing-Tip Vortex Using Laser Velocimetry”, NASA-TM 88343. 1987.

Takashi, M., F. Holzäpfel, and T. Gerz, "Wake Evolution of Wing-Body Configuration from Roll-Up to Vortex Decay", AIAA Paper 2012-0428.

Uzun, A., M.Y. Hussaini, C.L. Streett, “Towards Tip Vortex Noise Prediction by High-Order LES on Overset Grids”, AIAA Paper 2005-2865.

Vicroy, D.D., P.M. Vijgen, H.M. Reimer, J.L. Gallegos, P.R. Spalart, "Recent NASA Wake-Vortex Flight Tests, Flow Physics Database and Wake-Development Analysis," AIAA Paper 1998-5592. 